\title{
A Língua Latina e a precisão conceitual
}

\section{Thiago Soares de Oliveira ${ }^{1}$}

1 Doutorando e Mestre em Cognição e Linguagem pela Universidade Estadual do Norte Fluminense Darcy Ribeiro. Especialista em Língua Portuguesa pelo Centro Universitário Barão de Mauá (CUBM) e em Língua Latina e Filologia Românica pela Universidade Cândido Mendes (UCAM). Licenciado em Letras pela Universidade Castelo Branco (UCB). Professor do Instituto Federal Fluminense (IFF), Brasil. E-mail: so.thiago@hotmail.com

RESUMO: Este trabalho revisional, ligado ao campo terminológico, objetiva recuperar uma discussão fundamental em relação ao uso de termos latinos como forma de manutenção de precisão conceitual em determinados campos do saber como o Direito, por exemplo. Partindo da pesquisa bibliográfica como metodologia capaz de dar conta do escopo traçado, constrói-se o embasamento teórico para a análise de vocábulos e expressões latinos utilizados nas diversas searas do conhecimento especializado, bem como alguns já internalizados ao uso não técnico. Trata-se, pois, de um material analítico introdutório ao estudo dos vocábulos latinos.

Palavras-chave: Língua Latina; Léxico; Terminologia.

\section{The Latin Language and conceptual precision}

ABSTRACT: This revisional work on the terminological field, aims to recover a fundamental discussion regarding the use of Latin terms as a form of conceptual precision maintenance in certain fields of knowledge such as law, for example. From the literature as a methodology capable of handling the tracing scope, builds the theoretical basis for the analysis of words and Latin expressions used in various crops of expertise, and some have internalized the non-technical use. It is therefore an introductory analytical material to the study of Latin words.

Keywords: Latin Language; Lexicon; Terminology.

\section{CONSIDERAÇÕES INICIAIS}

A utilização da Língua Latina para denotar precisão conceitual em lugar de termos aportuguesados é típica de áreas do saber como o Direito, além de outros. Buscando a precisão de uma língua que não sofre as influências do tempo com tanta intensidade como as línguas românicas, família em que se inclui o Português, o conhecimento especializado encontra no Latim um nicho fértil de possibilidades.

Como o dinamismo e a vivacidade são e- lementos característicos das línguas (BAGNO, 2007, 2010; CUNHA; CINTRA, 2012), é de se esperar que, com o passar do tempo, modificações semânticas, bem como alterações de naturezas outras, sejam naturalmente implementadas de modo que não se possa garantir a fixidez de sentido de determinados termos e expressões. Ocorre que, buscando a exatidão de certas concepções, as áreas especializadas se valem da Língua Latina para estruturar seus jargões, especialmente porque tal idioma, a despeito da inestimável importância histórica, lin- 
guística e cultural, sofre menores pressões temporais, mantendo, assim, um conteúdo semântico menos mutável que as línguas modernas manejadas hodiernamente.

Em que pese a tal consideração sobre a suposta invariedade de sentido do léxico latino, os estudiosos das letras clássicas não apontam essa característica como sinal de morte do idioma. Na verdade, a tendência é a de que se considere o Latim como língua viva em razão do constante uso (FORTES, 2010; MELO, 2013; OLIVEIRA, 2015a; VIARO, 1999), inclusive na modernidade, motivo pelo qual este trabalho, por meio de obras específicas e da análise de vocabulário supostamente especializado, tenciona recuperar uma questão de vasta relevância para a seara terminológica: o uso da Língua Latina como elemento de precisão conceitual. Ademais, percebendo que cada área do saber possui seus próprios jargões, o que facilita a comunicação no meio especializado, discute-se a utilização do termo latino na manutenção de um significado específico durante um longo período de tempo.

Diante disso, com o propósito de rever parte da literatura concernente a esse assunto, este artigo dedica algumas páginas para o exame de termos cujas filiações justificam o uso do Latim na composição do léxico especializado. Esse olhar analítico recai não só sobre os termos jurídicos, mas também sobre outros que são empregados especializadamente por razões de herança histórica, sendo ou não de amplo uso e conhecimento.

\section{BREVES REFLEXÕES SOBRE TERMINOLO- GIA E LÉXICO ESPECIALIZADO}

Há diversas noções relacionadas à terminologia, o que dificulta a sua conceituação.
De forma prática e apropriada a este trabaIho, entender-se-á sinteticamente como um "conjunto de termos, ou vocabulário, de determinada especialidade" (DIAS, 2000, p. 90), conceito tratado amplamente por Pontes (1997) em trabalho dedicado à terminologia científica.

De acordo com Pontes (1997), a questão terminológica está intimamente relacionada à necessidade de nomear as novidades oriundas do avanço das ciências e da tecnologia. Nesse sentido, "toda atividade humana, todo domínio do saber implica um grande número de conceitos, por isso é preciso dominar um conjunto de nomes para conhecer, reconhecer e manipular as coisas" (PONTES, 1997, p. 48). De fato, é notável que as atividades especializadas comportam nomenclaturas peculiares como forma de construir um nicho comunicativo próprio, utilizado pelos pares não como meio de exclusão dos demais indivíduos, mas como maneira de atender as exigências do avanço científico. À guisa de exemplo, podem-se mencionar os vocábulos componentes do arcabouço lexical que tem sido denominado de "juridiquês", referência aos jargões utilizados pelos profissionais das diversas vertentes do Direito.

A rigor, "toda terminologia possui uma finalidade socioprofissional e serve prioritariamente para exprimir saberes temáticos" (BOULANGER, 1995, p. 1), razão pela qual "muitos dos termos técnicos não se encontram nos dicionários de língua corrente" (PONTES, 1997, p. 48). Isso não significa, todavia, uma intencionalidade de não compartilhamento de tecnicismos, mas indica o grau de especialização e o ambiente de empregabilidade de determinados vocábulos. É nesse sentido que a questão da terminologia deve ser objeto de reflexão cui- 
dadosa, especialmente porque indivíduos podem não compor certos nichos científicos especializados, mas deles necessitar para a resolução de impasses corriqueiros.

Exemplo disso seria uma hipotética situação de acesso de um sujeito comum ao conteúdo de uma sentença judicial, repleta de termos jurídicos, o que ilustraria bem a prudência necessária ao tratamento da questão terminológica. De qualquer forma, mesmo sem o conhecimento de tais termos de utilização supostamente precisa, o indivíduo comum teria em seu favor o profissional especializado. A propósito desse assunto, Oliveira (2015b, p. 15), ao se ocupar da questão do latinismo como terminologia, após analisar o caso específico da palavra campus, ressalta que "o Latim desponta claramente funcional no meio técnico, abrangendo, inclusive, os documentos oficiais", dada a necessidade da distinção entre o léxico primário (não técnico, comum) e o léxico terminológico (especializado).

O objeto da publicação de Oliveira (2015b), apesar de não estar relacionado diretamente à questão da precisão conceitual terminológica, mas ao uso do um latinismo específico, deixa o vislumbre de que a escolha lexical deve traduzir, com maior rigor possível, no âmbito especializado, o conceito a ser transmitido, evitando a ambiguidade, a contradição e a utilização de palavras vazias de sentido prático. A esse entendimento coaduna-se o de Lara (2004). Entendedora de que "o conceito é uma unidade abstrata criada a partir de uma combinação única de características", a autora percebe o termo "como uma designação que corresponde a um conceito em uma linguagem de especialidade" (LARA, 2004, p. 92).

Nota-se, nessa linha de raciocínio, que, afora as peculiaridades inerentes a cada um dos trabalhos, Boulanger (1995), Dias (2000), Lara (2004), Oliveira (2015b) e Pontes (1997) percebem de forma similar o papel do uso terminológico como uma especificidade relacionada a uma área do saber. Vale acrescentar, nesse ponto da tessitura bibliográfica, que "um termo [..] é uma palavra contextualizada no discurso, tendo, conseqüentemente, um referente de interpretação" (LARA, 2004, p. 92). Assim, não há que se dissociar a relação existente entre o conceito de terminologia e o uso do léxico especializado, já que, em suma, ambos são praticados de forma interdependente.

De mais a mais, é preciso ressaltar que, conquanto a terminologia delimite um campo especializado, não raro os vocábulos migram do espaço particularizado para o uso comum, ordinário. Situações desse tipo são percebidas quando são analisados vocábulos latinos que parecem não pertencer a um arcabouço lexical específico, estando mais vinculados a questões históricas do que a especialidades propriamente ditas. Segundo Rónai (1980, p. 11), "são fragmentos conservados ao acaso, mas suficientes para convencer-nos da incrível força de condensação e expressão do idioma dos romanos".

Brevemente recuperados, pois, alguns tópicos da discussão a respeito do uso da Língua Latina para efeitos de manutenção de precisão conceitual, passa-se à análise, com as devidas inserções bibliográficas que necessárias se fizerem, tanto de algumas expressões latinas que se pretendem precisas quanto de outras já internalizadas pelos indivíduos ou que migraram para o meio não técnico. 


\section{ANÁLISE DOS VOCÁBULOS E EXPRESSÕES LATINOS}

Entre as várias expressões latinas, algumas se destacam por terem se mantido dentro dos limites terminológicos, ou seja, são utilizadas em áreas específicas do conhecimento com o intuito de designar ou significar uma nomenclatura específica. Outras, no entanto, inicialmente próprias de uma área de estudo, passaram ao uso comum, corriqueiro, perdendo o caráter puramente especializado. Assim,

Entende-se que os termos são, antes de mais, unidades lexicais que assumem significados específicos quando usadas em discurso especializado, significados esses que lhes permitem denominar conceitos científicos e técnicos. Mais se entende que, para que uma unidade denomine um determinado conceito, ela deve ser portadora de um tipo de significado estrutural e/ou referencial que the permita essa capacidade denominativa (CORREIA, 2005, p. 1-2).

Isso significa que, às vezes, embora a estrutura seja mantida, assim como ocorre com os latinismos, é possível que a referência seja desviada para uma capacidade denominativa mais usual e menos especializada. Trata-se, na verdade, do próprio comportamento da língua, viva e dinâmica, em que pese à manutenção de termos designativos estanques nos vários âmbitos do conhecimento tais como o Direito, a Botânica e a Zoologia. Assim, considerando que o trabalho de Santos (2008) abarca muitas locuções e elementos latinos, seguem vinte outras expressões e termos não contemplados naquele trabalho, seguidos de sucintas explicações de nível morfológico, a par- tir da leitura das obras de Almeida (1992), Cardoso (2003) e Faria (1958):

- Alias: considerado um advérbio na Língua Latina, esse termo é utilizado em Língua Portuguesa como retificador, normalmente com o sentido de "de outro modo";

- Alibi: advérbio latino utilizado na seara do Direito, significando "em outro lugar", "em outro sentido";

- Alter ego: expressão da Psicanálise composta pelos pronomes alter (outro) e ego (eu), ou seja, "outro eu";

- A posteriori: significa "a partir do que vem depois", já que o advérbio posterius significa "posteriormente", "em seguida", "mais tarde";

- A priori: "a princípio", "a partir do que vem antes", do advérbio latino prius, que significa "em primeiro lugar", "antes", "de preferência";

- Agnus Dei: expressão religiosa que significa "o Cordeiro de Deus", pela composição de agnus (substantivo neutro da $2^{a}$ declinação no nominativo singular) e $D e i$ (substantivo masculino Deus, da 2a declinação no genitivo singular);

- Carpe diem: expressão latina atribuída ao período árcade, significando "aproveite o dia". Trata-se do verbo carpere (no imperativo) associado a diem, (dies, nome da 5a declinação no acusativo singular);

- Corpus Christi: expressão religiosa que significa "o Corpo de Cristo". Pode ser explicada por analogia com a expressão $a g$ nus Dei, exceto pelo fato de que o substantivo Deus, Dei, apesar de pertencer ao mesmo caso que agnus, declina-se de forma particular. De qualquer forma, tem-se corpus (nominativo singular neutro) e Christi (Christus, no genitivo singular); 
- Curriculum vitae: "o percurso de vida", "a trajetória de vida". Expressão já usual composta por curriculum (substantivo neutro da 2 a declinação no nominativo singular) e vitae (genitivo singular de vita, nome feminino da 1a declinação latina);

- Data venia: frequentemente empregada em documentos jurídicos, significa "com o devido respeito", "com a devida permissão". Trata-se de uma explicação um pouco mais complexa, em razão da junção de um particípio com um nome declinado no ablativo, apesar da queda da preposição cum, que, em Latim, era seguida desse caso. Por isso, data (particípio passado feminino singular de do, dare, que representa o verbo dar, em Português) e venia (substantivo feminino venia, veniae no ablativo singular, que coincide, na 1a declinação, com o nominativo e com o vocativo, ambos no singular). Literalmente, a expressão seria traduzida como "permissão dada, concedida";

- Exempli gratia (e.g.): trata-se de uma expressão idiomática latina, cujo significado é "por exemplo";

- Et caetera (etc): significa "e outros", sendo abreviado como "etc.". A expressão é composta pela conjunção et (e) e o advérbio caetera (quanto ao resto). Isso justifica o porquê de a gramática normativa recomendar que não se utilize "e" antes dessa expressão, sendo facultativo, porém o uso da vírgula. Além disso, reforça-se a necessidade da utilização do ponto abreviativo, obrigatório após "etc.";

- Honoris causa: "por causa da honra", "honorariamente". O substantivo causa, quando empregado no ablativo, equivale à locução prepositiva "por causa de" e rege o genitivo, motivo pelo qual honoris encontra-se no genitivo singular da 3 a declinação do substantivo masculino honor, honoris. Algumas universidades atribuem a pessoas reconhecidamente eminentes suas áreas de conhecimento o título de Doctor Honoris Causa;

- Fugere urbem: expressão composta pelo verbo fugire e urbs, urbis, substantivo feminino da terceira declinação no acusativo singular, normalmente traduzida como "fugir da cidade". Como esse verbo latino também pode significar "evitar", prefere-se a construção "evitar a cidade", caso em que o uso do acusativo fica mais bem delineado, por se tratar, neste caso, de um verbo transitivo direto. Ressalte-se, no entanto, que fugire é também equivalente a "fugir de";

- In memoriam: traduzido por "em memória de", ou seja, in (preposição latina que pode reger tanto o acusativo quanto o ablativo) acompanhado de memoriam (substantivo declinado no acusativo singular da 1a declinação);

- In vitro: "no vidro". Caso análogo ao anterior, à exceção da palavra vitro (de vitrum, vitri, que designa substantivo neutro da 2a declinação no ablativo singular);

- Ipsis litteris: "pelas mesmas letras". Expressão composta pelo pronome demonstrativo ipse, ipsa, ispsum no ablativo plural em concordância com o substantivo feminino da $1 \underline{\text { ạ }}$ declinação littera, litterae, também no ablativo plural. Trata-se de locução latina bastante usual tanto na fala e quanto na escrita;

- Locus amoenus: é uma característica atribuída ao período do Arcadismo e significa "lugar ameno". A composição da expressão se dá pelo substantivo masculino da 2 a declinação locus, loci no caso nominativo singular, seguida do adjetivo de $1^{\text {ạ }}$ classe correspondente; 
- Persona non grata: conjunto de palavras traduzido como "pessoa indesejada". Essa estrutura frasal latina é bem simples: persona (de persona, personae, substantivo feminino da 1a declinação no nominativo singular), non (advérbio anteposto ao adjetivo) e grata (de gratus, grata, gratum, que significa "agradável", adjetivo que, por ser de 1 a classe, concorda com persona em gênero, número e caso);

- Post scriptum (P.S.): expressão utilizada ao fim de cartas ou correspondências quando se quer acrescentar uma nova informação. A preposição post ("depois de") rege o acusativo; a palavra scriptum (de scriptum, scripti, neutro da 2 a declinação), portanto, encontra-se no acusativo singular.

Dentre os termos e expressões analisados, pode-se pontuar que alguns ainda não foram recepcionados totalmente pelo uso, tais como data venia e exempli gratia, componentes do léxico terminológico jurídico; outros, todavia, como alibi, a priori e a posteriori, já são amplamente empregados tanto na oralidade quanto na escrita; expressões como curriculum vitae, et caetera (etc.) e post scriptum (P.S.), por sua vez, são de uso corrente, ainda que a origem e o significado latinos sejam desconhecidos pelos indivíduos, especialmente nestes dois últimos. Acrescentem-se a estes as abreviaturas latinas A.M. (ante meridiem) e P.M. (post meridiem), mormente utilizadas em mostradores digitais de relógios norteamericanos. Em ambos os casos, a palavra meridiem, substantivo da 5á declinação latina, encontra-se no acusativo singular devido às regências das preposições ante e post.

Diante dessas análises, o posicionamento adotado neste trabalho se coaduna com o entendimento de Melo (2013, p. 61) no sentido de que "é inquestionável que o estudo do Latim viabiliza a compreensão de numerosas indagações linguísticas que se referem ao conhecimento das línguas românicas, podendo fornecer explicações para fenômenos aparentemente inexplicáveis do português". Quanto à precisão conceitual, em razão da resistência ao tempo, a Língua Latina parece bem empregada na delimitação de termos específicos.

\section{CONCLUSÃO}

Passando a breves comentários conclusivos, é preciso pontuar, no que se refere à relação entre a Língua Latina e a precisão conceitual, que o idioma dos romanos encontra-se espalhado pelas diversas áreas do saber, especializadas ou de uso corriqueiro. Em alguns casos, embora pareça específico, o significado do termo latino é facilmente identificado não só pela proximidade gráfica com a Língua Portuguesa, mas também porque o uso o consagra no ambiente não técnico.

Outro ponto relevante diz respeito ao fato de que a Língua Latina principiar o seu declínio no século I d. C. (fase clássica), passando a modalidade vulgar pela do romance até a formação da Língua Portuguesa. Nesse longo trajeto de transformação, alguns vocábulos latinos permaneceram intactos no manejo cotidiano dos falantes do Português, enquanto outros sofreram inúmeros cortes linguísticos, resultado em novas palavras. Das palavras mantidas, muitos foram aproveitadas como itens terminológicos que, supostamente, estariam menos sujeitos à ação do tempo do que o novo idioma românico em pleno desenvolvimento.

É preciso ressaltar também que não só 
Direito, de raízes latinas, vale-se do idioma dos romanos para fortalecer conceitualmente o seu arcabouço lexical, mas também a Literatura, as instituições religiosas, etc. Essa variedade de usos prova, de certa forma, que o estágio mais antigo da Língua Portuguesa, provavelmente devido ao prestígio, às qualidades e à baixa possibilidade de transformação, foi escolhido como mantenedor de expressões que necessitam de interpretação precisa. Em tese, outros idiomas do tronco itálico, aparentados do Latim, poderiam fazer as vezes de língua antiga de precisão conceitual, já que são considerados extintos. Ocorre que nenhum desses idiomas são portadores de prestígio cultural e antecessores do Português.

Por fim, fica o registro de que os vocábulos analisados poderiam formar o esboço de ínfimo inventário da Língua Latina, se fosse esta considerada morta neste trabalho. Ao contrário, pelo que se pode perceber, o uso constante nas diversas searas do saber, inclusive no meio não técnico, alça o Latim ao posto de sobrevivente, mesmo após séculos de transformação.

\section{REFERÊNCIAS}

ALMEIDA, N. M. de. Gramática Latina: curso único e completo. 24. ed. São Paulo: Saraiva, 1992.

BAGNO, M. Dramática da Língua Portuguesa - tradição gramatical, mídia \& exclusão social. 5. ed. São Paulo: Edições Loyola, 2010.

Nada na língua é por acaso: por uma pedagogia da variação linguística. São Paulo: Parábola Editorial, 2007.

BOULANGER, J. C. Alguns componentes linguísticos no ensino da terminologia. Ciência da Informação, Brasília, v. 24, n. 3, s/p,
1995.

CARDOSO, Z. de A. Iniciação ao Latim. 5. ed. São Paulo: Ática, 2003.

CUNHA, C.; CINTRA, F. L. Nova Gramática do Português Contemporâneo. 5. ed. Rio de Janeiro: Lexicon Editora Digital, 2012.

CORREIA, M. Terminologia, neologia e normalização: a terminologia em Portugal e países de língua portuguesa em África. Terminómetro, número especial, p. 1-13, 2005.

DIAS, C. A. Terminologia: conceitos e aplicações. Ciência da Informação, Brasília, v. 29, n. 1, p. 90-92, jan./abr. 2000.

FARIA, E. Gramática Superior da Língua Latina. Rio de Janeiro: Livraria Acadêmica, 1958.

FORTES, F. da S. A "língua" e os texto: gramática e tradição no ensino de Latim. Instrumento, Juiz de Fora, v. 12, n. 1, p. 63-70, jan./jun. 2010

LARA, M. L. G. Diferenças conceituais sobre termos e definições e implicações na organização da linguagem documentária. Ciência da Informação, Brasília, v. 33, n. 2, p. 91-96, mai./ago 2004.

MELO, P. A. G., O uso de expressões latinas como elementos de ornamentação na linguagem publicitária escrita no Português Contemporâneo. Interfaces, Guarapuava, v. 4, n. 2, p. 60-71, dez. 2013.

OLIVEIRA, T. S. de. A queda do gênero neutro do Latim: questiúnculas sobre a divergência entre o gênero real e o gênero gramatical. Philologus, Ano 21, n. 63, p. 22-32, Rio de Janeiro, CIFEFIL, set./dez. de 2015a. de. Do Latim ao Português moderno: a questão do latinismo como terminologia. Rónai - Revista de Estudos Clássicos e Tradutórios, Juiz de Fora, v.3, n. 2, p. 03-17, 2015b.

PONTES, A. L. Terminologia científica: o que 
é e como se faz. Revista de Letras, v. 19, n. 1/2, p. 44-51, jan./dez. 1997.

RÓNAI, P. Não perca o seu latim. Colaboração de Aurélio Buarque de Holanda Ferreira. Rio de Janeiro: Nova Fronteira, 1980.

SANTOS, G. M. dos. A cultura latina na contemporaneidade. Conferência da Academia de Letras da Bahia, abr./2008.

VIARO, M. E. A importância do Latim na atualidade. Revista de Ciências Humanas e Sociais, São Paulo, Unisa, v. 1, n. 1, p. 7-12, 1999.

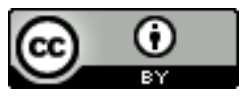

License information: This is an openaccess article distributed under the terms of the Creative Commons Attribution License, which permits unrestricted use, distribution, and reproduction in any medium, provided the original work is properly cited.

Artigo recebido em 07 de março de 2016.

Avaliado em 23 de junho de 2016.

Aceito em 24 de junho de 2016.

Publicado em 03 de novembro de 2016.

Como citar este artigo (ABNT):

OLIVEIRA, Thiago Soares de. A Língua Latina

e a precisão conceitual. Estação Científica (UNIFAP), Macapá, v. 6, n. 2, p. 09-16, maio/ago. 2016. 